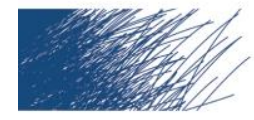

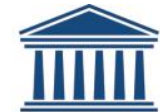 \\ UNIVERSITEIT \\ GENT
}

biblio.ugent.be

The UGent Institutional Repository is the electronic archiving and dissemination platform for all UGent research publications. Ghent University has implemented a mandate stipulating that all academic publications of UGent researchers should be deposited and archived in this repository. Except for items where current copyright restrictions apply, these papers are available in Open Access.

This item is the archived peer-reviewed author-version of: Identifying overarching excipient properties towards an in-depth understanding of process and product performance for continuous twin-screw wet granulation

Authors: Willicke N., Szepes A., Wunderlich M., Remon J.P., Vervaet C., De Beer T.

In: International Journal of Pharmaceutics, 522(1-2): 234-247

To refer to or to cite this work, please use the citation to the published version:

Willicke N., Szepes A., Wunderlich M., Remon J.P., Vervaet C., De Beer T. (2017) Identifying overarching excipient properties towards an in-depth understanding of process and product performance for continuous twin-screw wet granulation

International Journal of Pharmaceutics, 522(1-2): 234-247

DOI: 10.1016/j.ijpharm.2017.02.028 


\title{
Identifying overarching excipient properties towards an in-depth understanding of process and product performance for continuous twin screw wet granulation
}

\begin{abstract}
The overall objective of this work is to understand how excipient characteristics influence the process and product performance for a continuous twin screw wet granulation process. The knowledge gained through this study is intended to be used for a Quality by Design (QbD)-based formulation design approach and formulation optimization. A total of 9 preferred fillers and 9 preferred binders were selected for this study. The selected fillers and binders were extensively characterized regarding their physico-chemical and solid state properties using 21 material characterization techniques. Subsequently, principal component analysis (PCA) was performed on the data sets of filler and binder characteristics in order to reduce the variety of single characteristics to a limited number of overarching properties. Four principal components (PC) explained $98.4 \%$ of the overall variability in the fillers data set, while three principal components explained $93.4 \%$ of the overall variability in the data set of binders. Both PCA models allowed in-depth evaluation of similarities and differences in the excipient properties.
\end{abstract}

\section{Introduction}

Continuous twin screw wet granulation is a promising technology for the manufacturing of solid dosage forms, offering better process control, lean scale up and potential savings in drug substance and development time [1]. Given the different manufacturing principle and much shorter granulation times of continuous twin screw wet granulation compared to batch high shear wet granulation, fundamental knowledge about the suitability and processability of excipients for continuous twin screw wet granulation is needed in order to support a QbD-based formulation development. A thorough understanding of the influence of the formulation composition and excipient characteristics on both process performance and the drug product's critical quality attributes is a fundamental part in the product design [2]. A number of studies have been published which studied the excipient and formulation impact on drug product quality and performance for a continuous twin screw wet granulation process. The studied formulations mainly contained excipients such as lactose, microcrystalline cellulose, dicalcium phosphate, or mixtures of them. Different lactose grades were processed [3] [4] as well as lactose isomers [3]. As described by El Hagrasi et al. three lactose grades with different particle sizes showed comparable granule growth behaviour at varied liquid-to-solid (L/S) ratios [4]. Keleb et al. showed that the lactose particle size and particle morphology did not significantly affect the tensile strength of tablets, whereas the isomer type of lactose had an influence on the disintegration time of tablets [3]. Moreover, some papers addressed the raw material variability of formulations [5], [6]. The variation in the degree of crystallinity of different MCC batches were shown to influence the water uptake capacity during granulation and consequently the size distribution of granules [5]. Fonteyne et al. also showed that the variation in particle size of the active pharmaceutical ingredient (API) was correlated with the particle size of the produced granules and that micronized API decreased tablet porosity [6]. With the aim to investigate the behaviour of hydrophobic materials, APIs with different hydrophobicity were studied in a continuous twin screw wet granulation process by Li et al. The hydrophobicity of the API had very limited impact on its distribution in the granulate when a foamed binding agent was used [7]. Also formulations with high drug loads up to $90 \%$ were processable in a continuous twin screw wet granulation process [8]. Vanhoorne et al. and Thomson and O'Donnel performed continuous wet granulation experiments on controlled release formulations: using hydroxypropyl methylcellulose as hydrophilic matrix former resulted in tablets with sustained release over 16-20 hours independent of the investigated process and formulation parameters [9]. However, contradictory results in granule shape were obtained when applying controlled release excipients [9], [10].

Next to the impact of process parameters and the manufacturing technique, the selection of appropriate excipients and the composition of the formulation are the most important variables to design the drug product properties towards the defined quality target product profile (QTPP). A comparison of excipients with very different characteristics in the same study design remains challenging due to different requirements in e.g. L/S ratio processable range for each of the excipients [11]. Thus, most of the above referred studies included a limited variation in the formulation composition 
and the majority of the obtained scientific conclusions must therefore be considered formulation specific. One of the main drivers for this research was to study the impact of excipients with very different material properties in the same experimental design.

Overall the objective of this research work is to systematically investigate and understand the influence of excipient characteristics and formulation composition on granule and tablet attributes after continuous twin screw wet granulation. Figure 1 provides a stepwise overview of the systematic approach used in this study [12]. Steps 1-4 are summarized in this publication. The research work on subsequent steps (5-8) is on-going and data is not yet published.

First, potentially suitable pharmaceutical fillers and binders for the continuous twin screw wet granulation technology were selected (step 1). Next, an extensive characterization of physico-chemical properties and solid state characteristics was performed for the excipients in order to generate numerical values which describe their properties (step 2). A PCA was then accomplished on the data set aiming to identify the overarching properties of the excipients and to reduce the large number of excipient characteristics down to a few overarching properties (step $3 \& 4$ ). As a next step, excipients will be identified which represent best the overarching properties (step 5). These excipients will then be studied as factors in a DoE in order to understand their impact on granule and tablet properties. Ultimately, the resulting statistical model is expected to provide an understanding and prediction of the excipient impact on the performance of the continuous twin screw wet granulation process as well as on the granule and tablet properties (step 6-8).

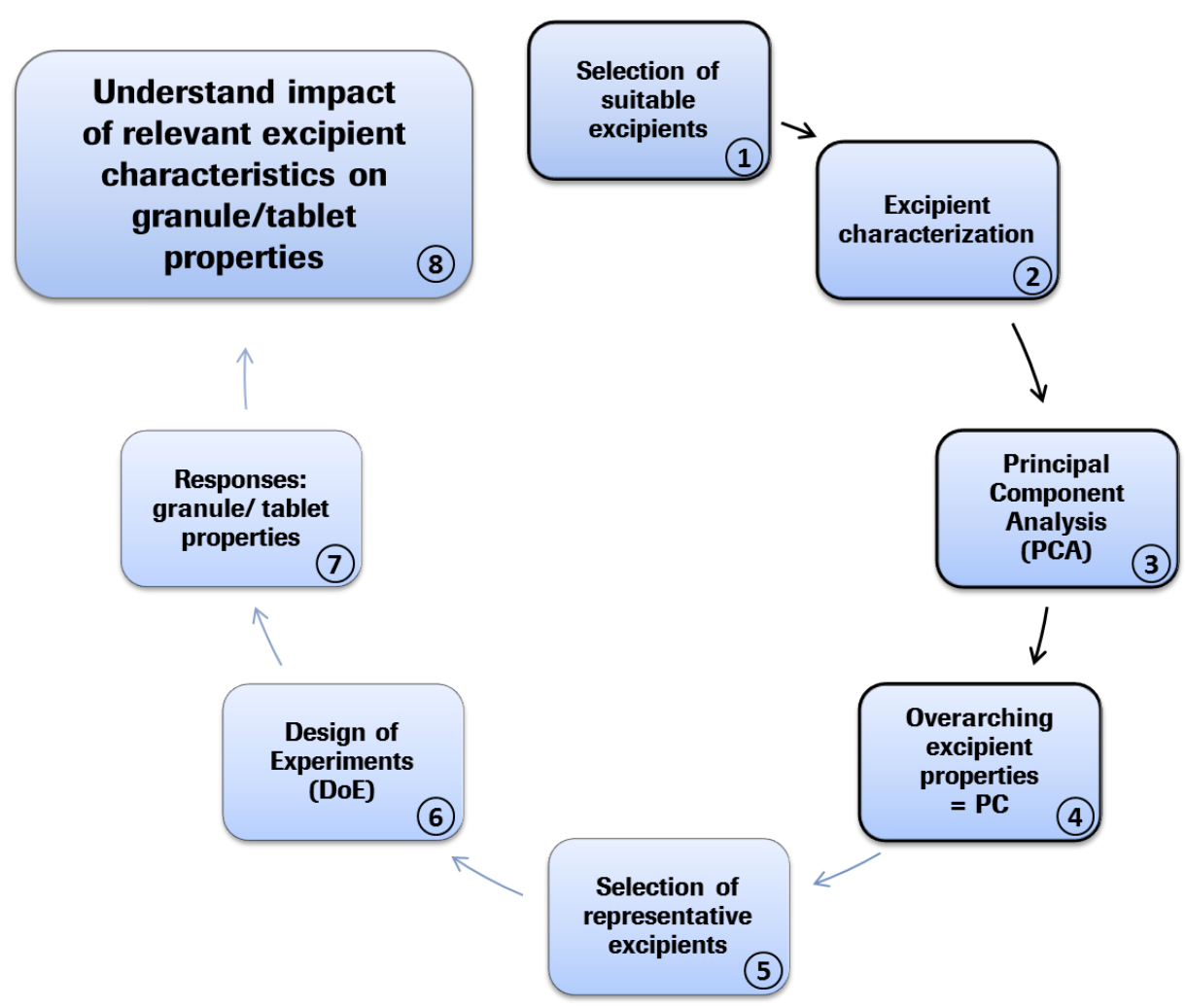

Figure 1. Stepwise overview of the systematic approach to generate formulation understanding

\section{Materials and Methods}

\subsection{Materials}

Microcrystalline cellulose (Avicel PH101, Avicel PH105, Avicel PH301, FMC Biopolymer, Philadelphia, USA), $\alpha-$ lactose monohydrate (Pharmatose 200M, Pharmatose 350M, DFE Pharma, Goch, Germany; GranuLac 200, Meggle Group, Wasserburg, Germany), mannitol (Parteck M200, Parteck Delta M, Merck, Darmstadt, Germany) and dicalcium 
phosphate anhydrous (FCC grade, Innophos, New Jersey, USA) were chosen as fillers. The investigated binders were hydroxypropyl methylcellulose (Pharmacoat 603, Pharmacoat 606, Pharmacoat 615, Shin Etsu, Tokyo, Japan), polyvinylpyrrolidone (Kollidon K30, Kollidon K90F, BASF, Ludwigshafen, Germany), hydroxypropyl cellulose (Klucel LF, Ashland, Kentucky, USA), vinylpyrrolidone-vinyl acetate copolymer (Kollidon VA64, BASF, Ludwigshafen, Germany), fully pregelatinized potato starch (Prejel PA5 PH, DFE Pharma, Goch, Germany) and maltodextrin (Maltrin 150M, Grain Processing Corporation, Iowa, USA).

\subsection{Methods for filler characterization}

\section{Particle Size Distribution}

Particle size distribution was characterized via laser diffraction (Malvern Mastersizer 2000, Malvern Instruments, Malvern, UK). Prior to the measurements, dicalcium phosphate was dispersed in demineralized water, while the other samples were dispersed in heptan and 0.2\% Span 80, and stirred at 2000rpm for 2 minutes (5 minutes for Parteck M200). Three parallel measurements were performed. The median particle size $\left(\mathrm{D}_{50}\right.$ in $\left.\mu \mathrm{m}\right)$ and the span of the particle size distribution were used as variables for the principle component analysis. The span of the particle size distribution was calculated as $\left(\mathrm{D}_{90}-\mathrm{D}_{10}\right) / \mathrm{D}_{50}$.

\section{Bulk and tapped density}

Bulk and tapped density were measured in triplicate using the tapping machine (Stampfvolumeter, J. Engelsmann, Ludwigshafen am Rhein, Germany). 30g of powder was weighed and its volume after $0\left(=V_{\text {bulk }}\right), 10,500$ and 1250 taps was documented. If the difference in volume between 500 and 1250 taps was larger than $2 \mathrm{ml}$, another 1250 taps were conducted. The density was calculated as the volume $V$ over the mass $m$ in $\mathrm{g} / \mathrm{ml}$. The compressibility index $C$ (in \%) was calculated as $\left(V_{\text {bulk }}-V_{\text {tapped }}\right) / V_{\text {bulk }} * 100$ where $V_{\text {tapped }}$ is the final volume after 1250 or 2500 taps.

\section{Moisture content}

An infrared dryer (Mettler LP16, Mettler-Toledo, Greifensee, Switzerland) in combination with a balance (Mettler PM480 Delta Range, Mettler-Toledo, Greifensee, Switzerland) was used to measure loss on drying (in \%). Three measurements were performed for each powder at a drying temperature of $90^{\circ} \mathrm{C}$ until the weight variation was below $2 \mathrm{mg}$ within $30 \mathrm{sec}$.

\section{Degree of crystallinity}

X-ray diffraction measurements were performed with a Philips X'Pert Pro powder diffractometer (model PW 3050/60). Diffractograms were recorded in the reflection mode in a 2-theta angular range of $8.5-40^{\circ}$ by steps of ca. $0.02^{\circ}$ at room temperature. The $\mathrm{Cu} \mathrm{K} \alpha$ radiation $(\lambda=1.5406 \AA)$ was generated at $45 \mathrm{kV}$ and $35 \mathrm{~mA}$. Diffractograms were recorded from rotating specimens using a position sensitive detector. Profile deconvolution was performed with a multiple peak fit tool using Origin's Peak Analyzer (OriginPro 9, Origin Lab). The fifth-degree polynomial function was used to fit the amorphous background (baseline), and the pseudo-Voigt function was used to express each crystalline reflection [13]. Cellulose crystallinity (in \%) was determined by calculating the ratio of the separated crystalline peak area to the total reflection area of all signals, including background.

\section{Particle Shape}

The analysis of particle shape was performed via high order image analysis (QICPIC, Sympatec, Clausthal-Zellerfeld, Germany). Prior to the measurements, dicalcium phosphate was dispersed in demineralized water, while the other samples were dispersed in heptan and 0.2\% Span 80 and stirred at 2000rpm for 2 minutes (5 minutes for Parteck M200). Particle shape analysis was performed in triplicate. The software Windox 5 was used to calculate the particle aspect ratio based on volume, which is defined as the ratio of the minimal to the maximal Feret diameter.

\section{True Density}

True density (in $\mathrm{g} / \mathrm{cm}^{3}$ ) was measured using a helium pycnometer (AccuPyc, Micrometrics, Norcross, USA). Ten purges at $19.5 \mathrm{psig}$ and ten runs at $19.5 \mathrm{psig}$ were conducted in one measurement. Two parallel measurements were performed. 


\section{Specific Surface Area}

The specific surface area (in $\mathrm{m}^{2} / \mathrm{g}$ ) was determined via nitrogen adsorption (Tristar II 3020, Micrometrics, Norcross, USA) in the validity range of the BET-isotherm. Samples were degassed at room temperature overnight before measurements were conducted $(n=2)$.

\section{Water sorption}

The water sorption behaviour of the fillers was measured using the Dynamic Vapor Sorption Equipment (Surface Measurements Systems, Middlesex, UK). Vapor sorption cycles were recorded from 0 to $80 \%$ humidity and back to $0 \%$ (desorption cycle) at a temperature of $20^{\circ} \mathrm{C}$. During the measurements, the moisture level was increased when the ratio of mass change over time was max. $0.002 \% / \mathrm{min}$. The maximum moisture uptake (in $\%$ ) at $80 \%$ humidity was used as a descriptor in PCA. Moreover the ratio (in $\mathrm{min} / \%$ ) of time to reach equilibrium at $80 \%$ humidity and the overall water uptake at $80 \%$ humidity was calculated as another descriptive variable for PCA according to the following equation (Eq.

6)

$$
\text { water uptake ratio }=\frac{t 80}{\frac{m 80-m 0}{m 0} * 100}
$$

where $t 80$ is the time needed (in $\mathrm{min}$ ) to reach the equilibrium state at $80 \%$ humidity, $m 80$ is the equilibrium mass (in g) at $80 \%$ humidity and $m 0$ the equilibrium mass (in g) at $0 \%$ humidity.

\section{Flowability}

Powders were measured in triplicate with a Ring Shear Tester RST-XS (Dr. Dietmar Schulze, Wolfenbüttel, Germany). A cell of $30 \mathrm{~cm}^{3}$ volume was used. A pre-shear of $1000 \mathrm{~Pa}$ and normal loads of $400 \mathrm{~Pa}, 600 \mathrm{~Pa}, 800 \mathrm{~Pa}$ and again 400 $\mathrm{Pa}$ were applied. The flow function coefficient $(f f c)$, which is the ratio of consolidation stress to unconfined yield strength, was used to characterize flowability [14].

\section{Dissolution kinetics}

Fillers were characterized regarding their dissolution rate in water. $4.00 \mathrm{~g}$ of water-soluble fillers, i.e. lactose and mannitol, was added to $50 \mathrm{~g}$ of water in a beaker stirring at room temperature. The endpoint of the dissolution test was set as the time when no particles were visually observed within 3 seconds. In order to increase the contrast, a black background was used. The measurements were repeated 5 times for each powder. The dissolution rate $D$ was calculated as $D=m_{\text {powder }} / t$, where $m_{\text {powder }}$ is the amount of powder to be dissolved (in $\mathrm{mg}$ ) and $t$ is the time (in sec) within which the powder was fully dissolved. For water insoluble fillers, i.e. dicalcium phosphate and MCC, a dissolution rate of $0.008 \mathrm{mg} / \mathrm{s}$ was applied in order to quantitatively reflect the 10000 -fold difference in solubility between water soluble and insoluble materials that is listed in the European Pharmacopoeia [15].

\section{Dynamic Hardness}

Rectangular tablets (2g tablet weight, $19 \mathrm{~mm}$ diameter) with a target solid fraction (SF) of 0.85 were compressed using a hydraulic press (Carver Press, GOT 1000, Mitsubishi, Carver, IN, USA). A maximum solid fraction (SF) of approximately 0.75 could be achieved for the tablets consisting of dicalcium phosphate anhydrate. Tablet SF was calculated from tablet mass $(m)$ in $\mathrm{g}$, volume $(V)$ in $\mathrm{cm}^{3}$ and true density $\left(\rho_{\text {true }}\right)$ in $\mathrm{g} / \mathrm{cm}^{3}$ according to Equation 4 . [16]

$S F=\frac{m / V}{\rho_{\text {true }}}$

Tablet dimensions were measured immediately after compression so that potential relaxation was not considered. True density was determined via helium pycnometry.

The deformation characteristics of the rectangular tablets were determined using the Pendulum Impact Device (PID II, PharmSci LLC, Kalamazoo, MI, USA). The dynamic hardness (in MPa), which is a measure of the ease with which a material irreversibly deforms when rapidly impacted, was calculated as follows (Eq. 5): 
Dynamic Hardness $=\frac{4 m g r}{\pi a^{4}} *\left(h_{i}-\left(\frac{3}{8}\right) h_{r}\right) * 10^{-6}$

where $m=$ mass of indenter in $\mathrm{g}, g=$ gravitational acceleration in $\mathrm{m} / \mathrm{s}^{2}, r=$ radius of indenter in $\mathrm{m}, h_{i}=$ initial height of indenter in $\mathrm{m}, h_{r}=$ rebound height of indenter in $\mathrm{m}$ and $a=$ radius of dent in $\mathrm{m}$. The measurements were made in triplicate, except for Avicel PH101 and PH105, for which two parallel measurements were performed.

\section{Wettability}

Wettability of the samples was determined via contact angle measurements using a Drop Shape Analyzer (DSA 100, Mettler-Toledo, Greifensee, Switzerland) applying the sessile drop method. The powders were compressed with a hydraulic press (Perkin-Elmer, Massachusetts, USA) at a pressure of $50 \mathrm{kN}$ for 30 seconds in a punch of $12 \mathrm{~mm}$ diameter. A $5 \mu 1$ drop of demineralized water was placed on each tablet. Contact angles (in ${ }^{\circ}$ ) were measured when the drop touched the surface of the tablet. Five parallel measurements were carried out.

\section{Dynamic flow of powders in motion}

The GranuDrum instrument (APTIS, Liège, Belgium) was used to measure the dynamic properties of the powders (such as flow angle and cohesive index) as a function of the rotating speed. The experimental set-up was a cylindrical drum (10mm diameter and $84 \mathrm{~mm}$ length) rotating around its horizontal axis [17]. Prior to analysis the drum was filled with approximately $30 \mathrm{ml}$ of the powder sample. The rotating drum was monitored with a chargecoupled device camera during the measurements. For each angular velocity, 50 images of the powder pile were recorded at $0.5 \mathrm{~s}$ intervals. The average position of the air-powder interface and its fluctuations were computed using a dedicated image processing algorithm. The fluctuations, which were calculated as the standard deviation of the 50 measurements at a certain rotation speed, are related to the cohesion of the powder. The dynamic angle (in ${ }^{\circ}$ ) was measured in the centre of the flow based on the average interface position. The controlled rotating speed mode was used with a linear increase of the rotating speed from 0 to $20 \mathrm{rpm}$ (up curve) and a decrease to zero (down curve) (no stop in between). The flow angle and the cohesive index at 10rpm drum rotation speed were used for the PCA. To evaluate the influence of drum speed on the powder flow behaviour, the drum speed was plotted against the flow angle and the cohesive index. The slope of the resulting trendlines was also used as a variable in the PCA representing the change of powder flow behaviour upon motion.

\section{Electrostatic charge of powders}

The triboelectric charge, which is built up in the powder samples while flowing on a stainless steel surface, was quantified with the GranuCharge instrument (APTIS, Liège, Belgium) equipped with an INOX $316 \mathrm{~L}$ tube. The initial charge density of the powder sample was measured after sampling. After a controlled flow inside a vibrating conduit the final charge density of the samples were determined. The difference between the initial charge density and the charge density after flow (in $\mu \mathrm{C} / \mathrm{kg}$ ) was calculated and used as variable for PCA.

\section{Powder cohesiveness}

The FT4 Powder Rheometer (Freeman Technology, Gloucestershire, UK) was used to measure cohesiveness of the excipients. The aeration test sequence records the consumed total energy (in $\mathrm{mJ}$ ) at $0,0.5,1,2,3,4,5$ and $6 \mathrm{~mm} / \mathrm{s} \mathrm{air}$ velocity at a constant blade tip speed of $100 \mathrm{~mm} / \mathrm{s}$. The Aeration Ratio (AR) was calculated as a descriptive value from

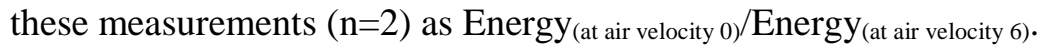

\section{Molecular weight and solubility}

The values for molecular weight (in Da) and solubility in water (in \%) were taken from the literature [18]. The values that were used for the principal component analysis are summarized in Table 4 in the appendix. 


\subsection{Methods for binder characterization}

\section{Viscosity}

The dynamic viscosity of the aqueous binder solutions was measured using a rotational viscosimeter (Modular Compact Rheometer Series 102, PP50, Anton Paar, Graz, Austria) with the plate-plate technique applying a gap size of $1 \mathrm{~mm}$ and a temperature of $20^{\circ} \mathrm{C}$. Three dispersions with different concentrations were investigated for each binder. Varying ranges of shear rate were applied, ranging from 0.1 1/s to 2000 1/s, depending on the viscosity of the liquid. As it was not possible to completely disperse Prejel in water without lumps, no viscosity results could be generated for Prejel. The concentrations for viscosity measurements were selected according to the liquid concentrations established in the literature which cover the range of typical binder concentrations applied in wet granulation processes (Table 1). The viscosity of Kollidon K30, Kollidon K90 and Kollidon VA64 was in addition to the concentrations indicated in Table 1 measured at $8 \%$ concentration in order to have comparable values available for PCA at equal concentrations for all binders. $8 \% \mathrm{w} / \mathrm{w}$ was selected for comparability reasons as a medium concentration at which it was possible to produce a binder liquid for all binder types and grades included in this study. The viscosity values (in mPas) measured at $8 \%$ w/w concentration were used as descriptive values in the PCA.

Table 1. Concentrations of binder dispersions for viscosity measurements

\begin{tabular}{|llll|}
\hline Binder & \multicolumn{2}{l|}{ Concentration $(\% \mathrm{~m} / \mathrm{m})$} \\
\hline Pharmacoat 603 & 4 & 8 & 14 \\
Pharmacoat 606 & 4 & 8 & 14 \\
Pharmacoat 615 & 2 & 4 & 8 \\
Klucel LF & 4 & 8 & 12 \\
Kollidon K30 & 5 & 12.5 & 20 \\
Kollidon K90F & 5 & 10 & 15 \\
Kollidon VA 64 & 5 & 12.5 & 20 \\
Maltrin M150 & 8 & 29 & 50 \\
\hline
\end{tabular}

The viscosity slope was calculated as an additional descriptive value in order to reflect changes in viscosity as a function of the binder concentration. Accordingly, the concentration of the binder solution was plotted against the logarithmic viscosity and the slope of the resulting linear graph was used for PCA.

\section{Glass transition temperature}

Glass transition temperature $\left(T_{G}\right.$ in $\left.{ }^{\circ} \mathrm{C}\right)$ of the binders was determined via modulated differential scanning calorimetry (Modulated Differential Scanning Calorimeter Q2000, TA Instruments, Zellik, Belgium). Non-hermetic Tero $_{\text {Zluminium }}$ pans and lids were used. Equilibration was done at $-20^{\circ} \mathrm{C}$ and a heat rate of $2^{\circ} \mathrm{C} / \mathrm{min}$ was applied. Maltrin M150 was dried for 24 hours at $37^{\circ} \mathrm{C}$ prior to the measurement. Heat-cool-heat cycles were applied where needed in order to detect the $T_{G}$ thoroughly (Table 2). Since the $T_{G}$ of Prejel cannot be determined by DSC [19], a value was taken based on supplier information [20]. 
Table 2. Settings for MDSC measurements

\begin{tabular}{|lll|}
\hline Binder & Heated up to $\left(\right.$ in $\left.{ }^{\circ} \mathrm{C}\right)$ & Cycle \\
\hline Klucel LF & 240 & heat - cool - heat \\
Pharmacoat 606 & 220 & heat - cool - heat \\
Pharmacoat 615 & 220 & heat - cool - heat \\
Pharmacoat 603 & 220 & heat \\
Kollidon K30 & 200 & heat \\
Kollidon K90F & 210 & heat \\
Kollidon VA 64 & 170 & heat \\
Maltrin M150 & 220 & heat \\
\hline
\end{tabular}

\section{Surface Tension}

$8 \%(\mathrm{w} / \mathrm{w})$ aqueous solutions of the binders were prepared. Kollidon VA64 was pre-treated in an ultrasonic bath for 90 minutes to ensure complete dispersion of the polymer. The density of the solutions (in $\mathrm{g} / \mathrm{ml}$ ) was determined using a $10 \mathrm{ml}$ glass pycnometer (Duran) as $m / V$ where $m$ is the mass of the binder liquid in $\mathrm{g}$ and $V$ is the binder liquid volume in $\mathrm{ml}$. The surface tension of the solutions (in $\mathrm{mN} / \mathrm{m}$ ) was determined with the pendant drop method in air using a drop shape analyzer (Drop Shape Analyzer 30, Krüss, Hamburg, Germany). Each measurement was conducted at room temperature in triplicate.

\section{Molecular weight}

The values for molecular weight (in Da) were taken from the literature. The values that were used for the principal component analysis are listed in Table 5 in the appendix.

\subsection{Principal Component Analysis}

A PCA was performed using the fillers` and binders` data set of quantified excipient characteristics separately with the SIMCA $^{\odot}$ software (Umetrics, version 14). Data were centred and scaled to unit variance. A logarithmical (log) transformation of variables is suitable for conversion of a non-normal distributed into a normally distributed data set in order to improve the data analysis efficiency [12]. Log-transformation was performed if needed. For interpretation of the principal components the loading plots were used.

For cross-validation, the data set was split up into 7 subsets. The subsets were step-wise systematically removed from the data set and the missing data points were then predicted based on the model terms and compared with the actual values. The closer the predicted value was to the actual value, the better was the model predictability and the larger the resulting $\mathrm{Q}^{2}$-bars.

\section{Results and Discussion}

\subsection{Selection of suitable excipients}

9 fillers and 9 binders were selected for this study. The selection of fillers included commonly used types for wet granulation processes with differences in chemical nature (e.g. lactose, MCC, mannitol and dicalcium phosphate) and properties like water solubility or compression behaviour (brittle/plastic). In order to achieve a wide variability in excipient characteristics, different filler grades were selected to account for differences in particle size (e.g. Pharmatose $200 \mathrm{M}$ vs. Pharmatose 350M) and density (e.g. Avicel PH101 vs. Avicel PH301). Likewise the selection of binders was based on the purpose to cover the different chemical nature of the most commonly used binders for wet granulation 
processes such as hydroxypropyl methylcellulose (HPMC), polyvinylpyrrolidone (PVP) and hydroxypropyl cellulose (HPC). Maltodextrin is of interest as binder for paediatric formulations since it can improve the mouthfeel and help to counteract bitter flavours [21]. Overall, the selected excipients covered broad material property attribute ranges with the idea that also attributes of excipients that were not included in this study are within these ranges. Thus, the expectation is that a future model would also allow predictions of the impact of non-selected excipients on drug product performance.

\subsection{Excipient characterization}

The intention was to perform a holistic excipient characterization of the selected 9 fillers and 9 binders such that all properties which might possibly influence the process or product performance during wet granulation as well as the resulting potential critical quality attributes (pCQAs) of the drug product were expressed in numerical values. The excipients were characterized by applying the methods described in section 2.2 and 2.3. The results of the excipient characterization are summarized in Table 4 and Table 5 in the appendix. An overview of all characteristics is provided in Table 3.

Table 3. Overview of determined filler and binder properties and characterization test methods

\begin{tabular}{|c|c|c|}
\hline & Descriptor & Applied method for characterization \\
\hline \multirow{23}{*}{ 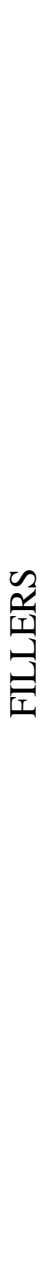 } & Median particle size (D50) & Laser diffraction \\
\hline & Span of particle size distribution & Laser diffraction \\
\hline & Bulk density & Tapping machine \\
\hline & Compressibility index & Tapping machine \\
\hline & Moisture content & Loss on drying via infrared dryer \\
\hline & Degree of crystallinity & $\mathrm{X}$-ray diffraction \\
\hline & Shape of particles & High order image analysis (QICPIC) \\
\hline & True density & Helium pycnometry \\
\hline & Specific surface area & Nitrogen adsorption (BET) \\
\hline & Amount of water uptake & Dynamic vapor sorption (DVS) \\
\hline & Water uptake ratio & Dynamic vapor sorption (DVS) \\
\hline & Flowability & Ring shear tester \\
\hline & Molecular weight & Literature \\
\hline & Solubility in water & Literature \\
\hline & Dissolution kinetics & Powder dissolved in water \\
\hline & Dynamic Hardness & Pendulum impact device \\
\hline & Wettability - Contact angle & Drop shape analyzer (sessile drop method) \\
\hline & Dynamic flow - flow angle & Rotating drum with camera (GranuDrum) \\
\hline & Dynamic flow - cohesive index & Rotating drum with camera (GranuDrum) \\
\hline & Dynamic flow - change of flow angle & Rotating drum with camera (GranuDrum) \\
\hline & Dynamic flow - change of cohesive index & Rotating drum with camera (GranuDrum) \\
\hline & Electrostatic charge & Triboelectric charge after motion (GranuCharge) \\
\hline & Cohesiveness & Powder rheometer \\
\hline \multirow{5}{*}{ 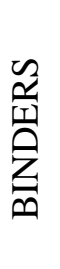 } & Dynamic Viscosity & Rotational viscosimeter \\
\hline & Change in Viscosity & Rotational viscosimeter \\
\hline & Molecular weight & Literature \\
\hline & Glass transition temperature & Differential scanning calorimetry \\
\hline & Surface tension & Glass pycnometer \\
\hline
\end{tabular}




\subsection{Principal Component Analysis (PCA) and identification of overarching excipient properties}

\subsubsection{PCA of fillers}

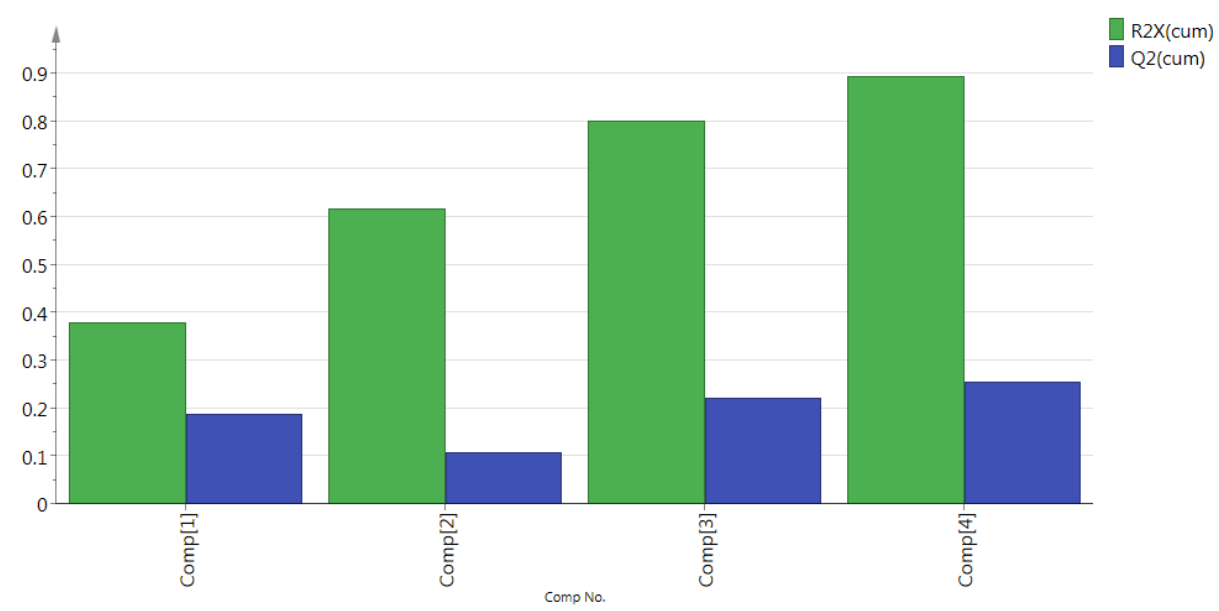

Figure 2. Summary of fit (fillers)

A four PC model was fitted for the fillers` data set. The green $\mathrm{R}^{2}$-bars in Figure 2 represent the cumulative percentage of variation that was explained by the model for each component separately. The closer the bar is to 1.0 the more perfect the fit of the model is. Here, the first PC explained 38.0\%, the second PC $23.8 \%$, the third PC $18.3 \%$ and the fourth PC $9.4 \%$ of the overall variability in the data set. A total of $89.4 \%$ variability was thus explained by the 4 PCs. Typically a number of 2-5 PC is adequate to explain the variation in a data set well. All PCs are orthogonal to each other and their importance descends from the first to the last PC [12]. The blue $\mathrm{Q}^{2}$-bars in Figure 2 indicate how well the model predicts new data. It is determined by cross-validation. The larger the $\mathrm{Q}^{2}$-bar is the better is the predictive power of the model. The addition of another 5th PC did not strongly contribute to higher $\mathrm{R}^{2}$-values and $\mathrm{Q}^{2}$-values (data not shown). Therefore a number of $4 \mathrm{PC}$ was considered appropriate in order to explain the majority of the variation for the data set.

All data points of the multidimensional model space in a PCA are projected on a plane which is spanned by two principal components. Each data point thus has a vector for the two principal components that explains its location on the plane: the scores. Hence, the scores plot displays the relationship of the excipients on the projection plane. The relation among the excipient properties (which are the variables) is explained by the loading plot. It depicts if variables are related (positively or negatively correlated) or if they are not related to each other. Moreover, loadings show the importance of the excipient properties for the principal components and provide information about the direction of the projection plane in the model space. Each PC can be interpreted as an overarching property which represents specific underlying excipient characteristics (i.e. the variables). The loading plots were used to assign an overarching property to each PC. Variables with large positive or negative loadings strongly influence the PCs, whereas variables located close to the origin of the loading plot are not well explained by the model and are therefore not relevant for the respective PCs in the plot (Figure 3 and Figure 4).

By applying PCA, the originally 23 variables could be condensed and reduced to 4 overarching properties (PC) which were in orthogonal relation to each other.

\section{PC1: moisture-related properties}

The filler characteristics, such as bulk density, dissolution rate, degree of crystallinity, solubility, aspect ratio and water uptake ratio had strongly negative PC1 loading values and were located on the left side of the loading scatter plot. Moisture uptake, LOD, molecular weight, flow angle and slope_FA, however, had strongly positive PC1 loading values 
and were located on the plots` right side (Figure 3). All of the above-mentioned variables were hence well explained by the model and thus strongly contributing to PC1. The majority of the properties with strongly positive or negative PC1 loading values were identified to be moisture-related properties.

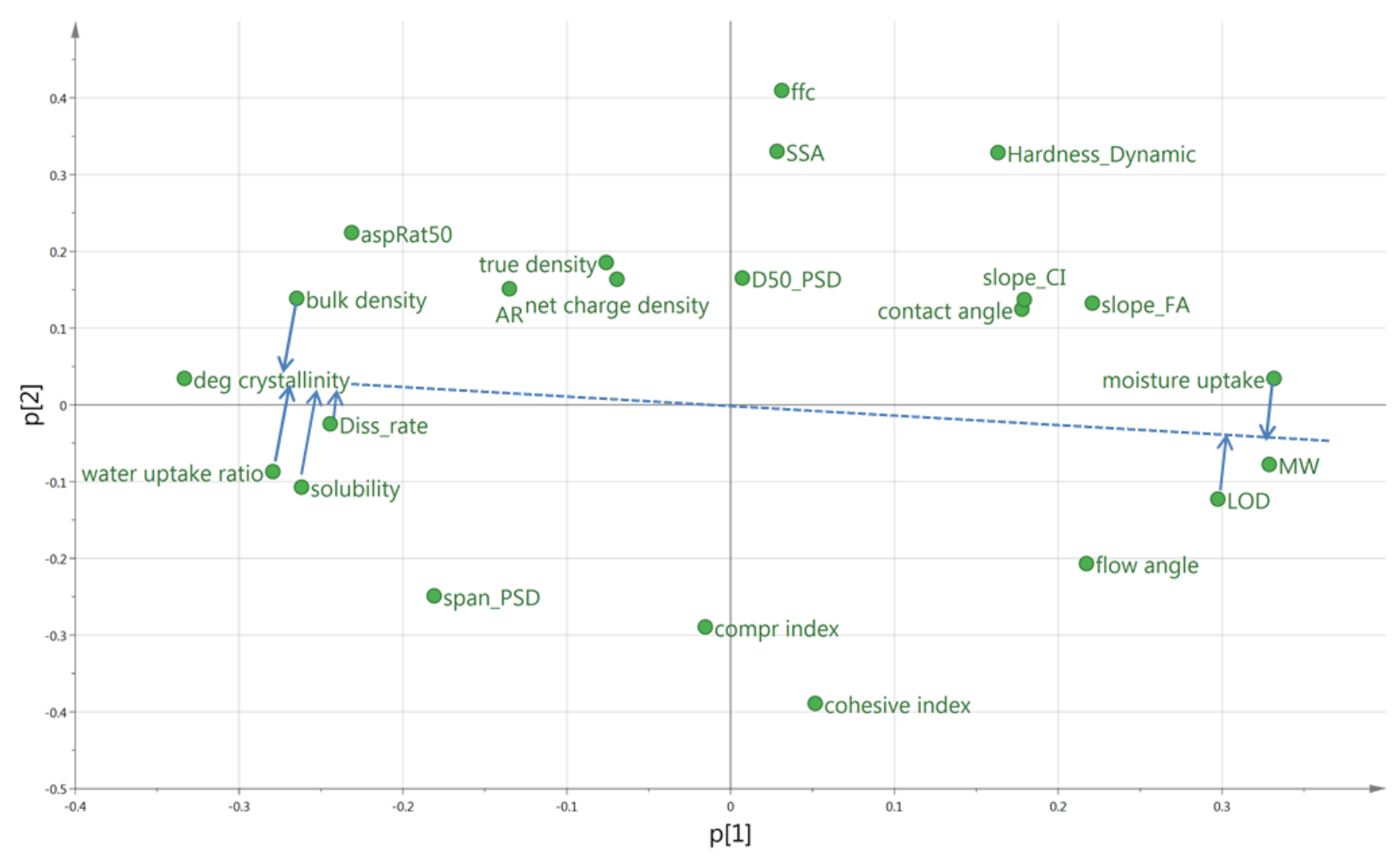

Figure 3. Loading scatter plot of fillers` $1^{\text {st }}$ and $2^{\text {nd }} \mathrm{PC}$

\section{PC2: flow-related properties}

The characteristics that significantly contributed to PC2 were ffc, specific surface area and dynamic hardness which had strongly positive PC2 loading values (upper part of plot) in contrast to cohesive index and compressibility index with negative loading values for PC2 (lower part of plot, see Figure 3). Consequently, the second PC was identified to represent the flow-related properties of the filler data set. 


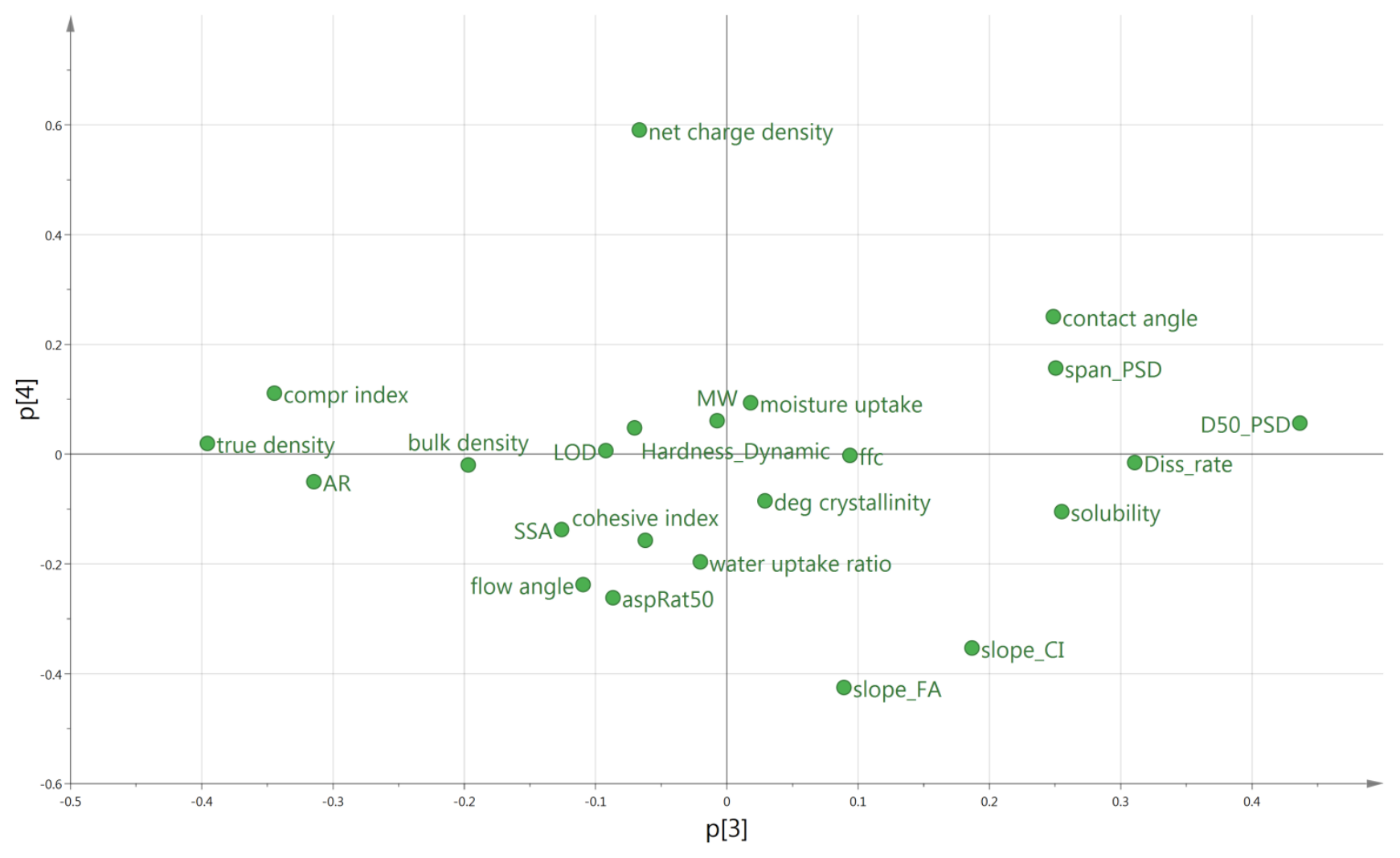

Figure 4. Loading scatter plot of fillers` $3^{\text {rd }}$ and $4^{\text {th }}$ PC

\section{PC3: density/particle size-related properties}

PC3 mainly explained the variability in particle size (D50) and dissolution rate as well as true density, compressibility index and aeration ratio (Figure 4). Accordingly, it was concluded that PC 3 represented density/particle size-related properties.

\section{PC4: charge/adhesion-related properties}

PC4 mainly explained the variability of the following characteristics in the filler data set: net charge density as well as slope_FA and slope_CI (Figure 4). PC4 was therefore identified to represent the charge/adhesion-related properties in the fillers data set.

Ultimately, PCA is a useful tool to understand the relation between variables in complex data sets. The loading scatter plots describes if characteristics are correlated or anti-correlated with regards to the respective PCs. To visualize this clearly per variable, an imaginary line is drawn starting from a selected variable (in the example degree of crystallinity was selected) through the plots` origin (Figure 3). Other variables can then be projected on this line. Variables located close to degree of crystallinity on the imaginary line are positively correlated with degree of crystallinity while they are anti-correlated when being projected on the line at the other side of the plot. The closer the projection gets to the plots` origin, the weaker the correlation is. In the given example a high degree of crystallinity was associated with a fast dissolution rate, high solubility and a high water uptake ratio (i.e. a positive correlation between the variables). In contrast, a low moisture uptake and LOD were linked to a high degree of crystallinity, in other words these variables were anti-correlated with degree of crystallinity. The relations among the mentioned variables were reasonable in view of common pharmaceutical knowledge, e.g. a lower degree of crystallinity was linked to a higher water binding capacity [5] which also corresponded to a higher moisture uptake. As a further example, the correlation between bulk density and degree of crystallinity could be explained as a result of the molecular order: crystalline materials have a higher degree of structural order and thus also a higher density compared to amorphous materials which leads to higher bulk density for fully crystalline materials. 
This procedure of identifying variables that are correlated or anti-correlated in the data set can be followed for any variable in a similar way.

In conclusion, all filler characteristics were considered relevant for the PCA model. Variables which are not relevant for the model should be located in or close to the origin in both loading scores plot of PC1 vs. PC2 as well as PC3 vs. PC4. In the PC3 vs. PC4 loading plot some variables such as molecular weight and degree of crystallinity were located close to the origin, however both were important for PC1.

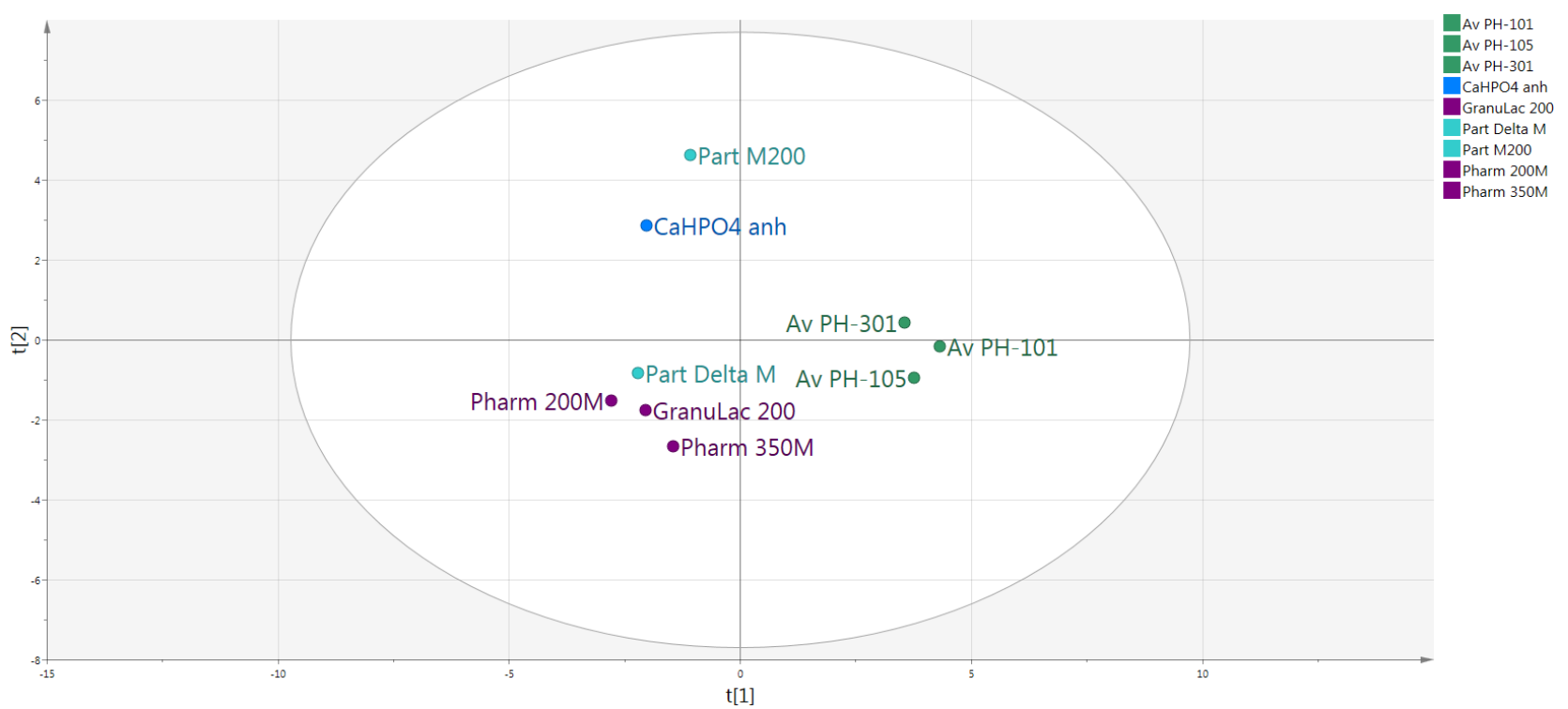

Figure 5. Scoresplot PC1 vs PC2 (fillers) - Colours indicate chemical nature of fillers

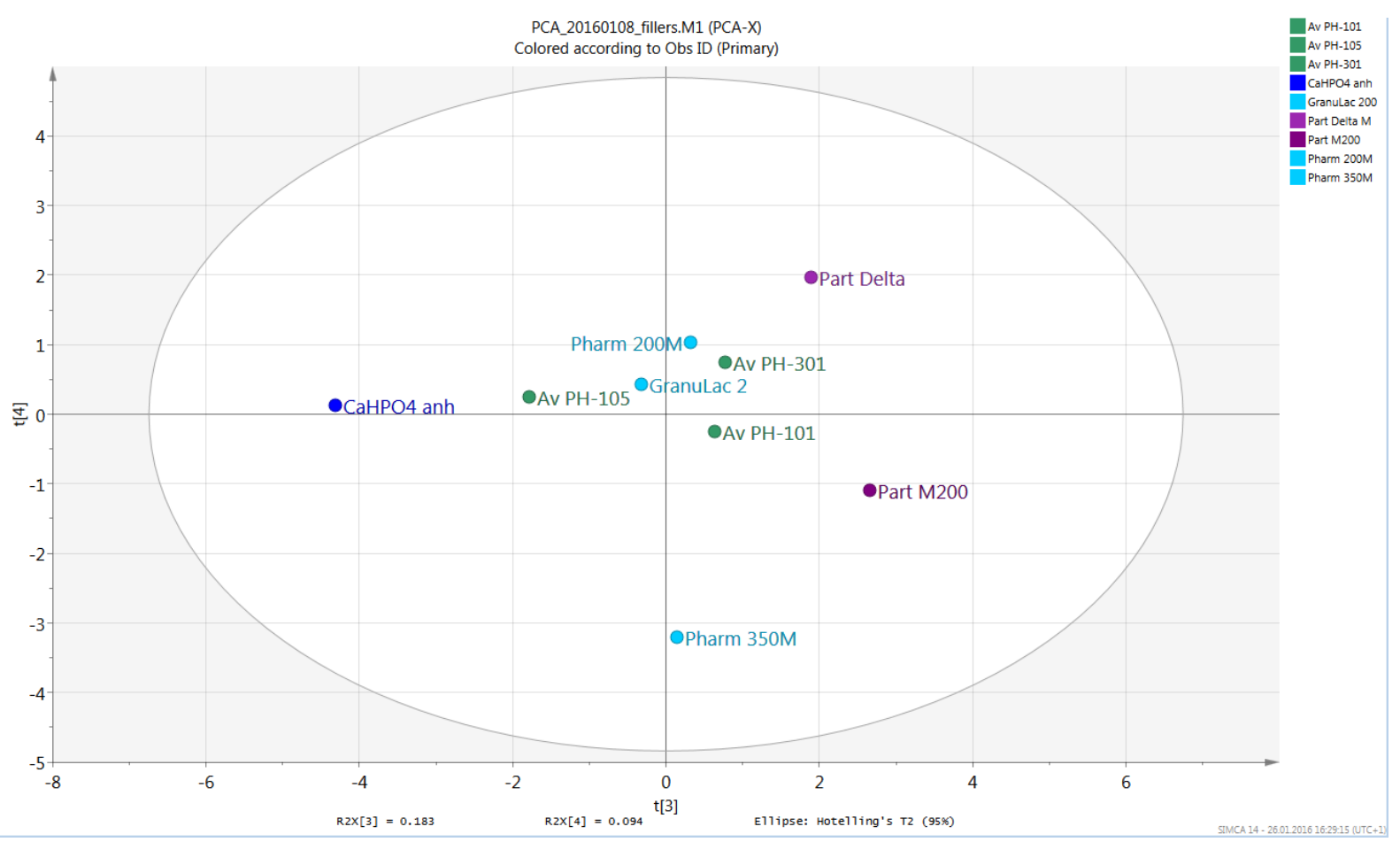

Figure 6. Scores plot PC3 vs PC4 (fillers) - Colours indicate chemical nature of fillers

The PC 1 versus PC 2 scores plot showed the relationship between the different filler types according to their principal properties (Figure 5). In the scores plot, the fillers which exhibit similar properties regarding the plotted overarching 
properties (i.e. loadings) were clustered, while fillers which were distinctly different in their properties were located on opposite sides of the plot. The MCC and lactose grades were grouped according to their chemical nature, while both mannitol types did not form a cluster. The MCC grades revealed the most positive score values for the first PC. As according to the PC1 vs. PC2 loading plot (Figure 3) the first PC represented moisture-related filler properties, the MCC grades were different in their moisture-related loading values which resulted in high PC1 score values compared to all other filler types (low PC1 score values). This statement was confirmed when inspecting the raw data: Avicel grades had for example higher LOD values (3.1-4.1\%) compared to other fillers (0.1-0.5\%) which explains the higher PC1 score values for Avicel grades since the LOD loading values did positively contribute to PC1 (LOD value and the score value of PC1 were positively correlated) (see Figure 3). The same fact was observed for degree of crystallinity where Avicel grades had low degree of crystallinity values (54-57\%) compared to the other fillers which were fully crystalline. Since the degree of crystallinity was anti-correlated with the PC1 score values, a low degree in crystallinity resulted in high PC1 scores and hence explained the high PC1 score values of Avicel grades.

Plotting the PC3 against PC4 scores (Figure 6) illustrated the differences among the MCC grades: Avicel PH101 and PH301 were clustered at equal PC3 score values whereas Avicel PH105 was located at lower PC3 score values. As depicted in the PC3 vs PC4 loading plot (Figure 4) variables like D50, dissolution rate, true density, AR and compressibility index strongly loaded into PC3. Referring to the raw data of excipient characterization there was neither a distinct difference among the Avicel grades in true density $\left(1.55-1.57 \mathrm{~g} / \mathrm{cm}^{3}\right)$ nor in dissolution rate $(0.008 \mathrm{mg} / \mathrm{sec}$ for all Avicel grades). However, Avicel PH105 had a lower D50 $(19 \mu \mathrm{m})$ compared to Avicel PH101 $(61 \mu \mathrm{m})$ and Avicel PH301 $(63 \mu \mathrm{m})$ as well as a higher compressibility index (34.6\%) and aeration ratio (42.02) compared to Avicel PH101 (25.95\% and 10.76, respectively) and Avicel PH301 (23.45\% and 15.11, respectively). Thus, the difference in median particle size D50, compressibility index and AR mainly explained the lower PC3 score values of Avicel PH105 compared to the two other Avicel grades. Parteck M200, a mannitol grade designed with excellent flowability [22], showed a high score value for PC2, representing flow-related properties. The superior flow properties of Parteck M200 compared to the other fillers were hence confirmed by the PCA model. Some of the fillers were located close to the origin of the PC3 versus PC4 scores plot which indicated that they had average properties in terms of density/particle size-related as well as charge and adhesion-related characteristics. In contrast to the PC1 versus PC2 scores plot, excipients were not clustered by their chemical nature in the PC3 versus PC4 scores plot. Hence, excipients of the same chemical group (e.g. lactose, mannitol, etc.) were heterogeneous with regards to their PC3/PC4 score values and thus different in their density/particle size-related properties and charge/adhesion-related properties.

Dicalcium phosphate anhydrate had a substantially higher density compared to other fillers since it had a lower score value for PC3 which was in accordance with the earlier described finding that density-related properties were mainly represented in PC3. In contrast to other fillers, Pharmatose 350M revealed a distinctly lower net charge as confirmed by its low PC 4 scores value. Both, the PC 1 versus PC 2 and PC 3 versus PC 4 scores plot showed that Pharmatose 200M and Granulac 200 were strongly correlated and had comparable properties since they were clustered (Figure 5 and Figure $6)$.

The PCA approach can not only be used to highlight which excipients possessed similar properties but also to identify those properties for which two fillers of interest differ the most. For example, Parteck M200 and Parteck Delta M were not clustered in the scores plots, although they were both mannitol grades. A contribution plot depicts the differences for all model terms in scaled units between two selected observations. According to the contribution score plot of Parteck Delta M and Parteck M200 (Figure 7), Parteck Delta M particularly exhibited a higher cohesive index, lower ffc value, smaller specific surface area, lower value for aspect ratio, higher value for compressibility index and broader particle size distribution. The differences in the above-mentioned properties allowed to conclude that Parteck Delta M possessed inferior flowability compared to Parteck M 200. 


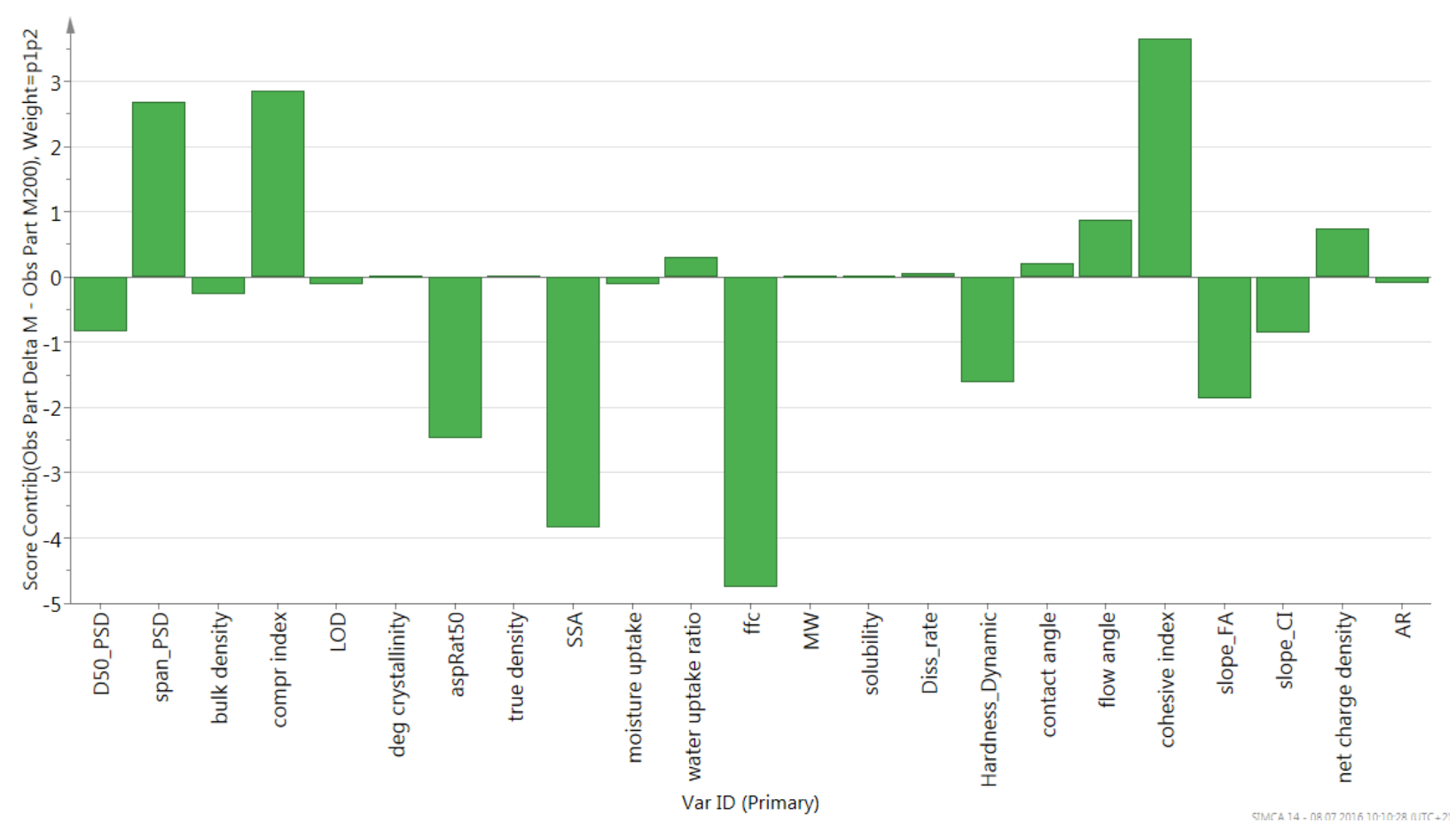

Figure 7. Contribution plot for comparison of Parteck M200 and Parteck Delta M - The larger the bar, the more the two filler differ in the given property

\subsubsection{PCA of binders}

Binders are commonly used in aqueous dispersions during wet granulation processes, where the physico-chemical characteristics of the dispersion are essential with regards to their influence on the product quality attributes. Therefore, no solid state characterization was performed for the binders and the data generated for the binders was mainly related to the hydrated state of the polymers in an aqueous environment. Hence, a reduced number of binder characteristics was measured compared to the fillers (see Table 3). Three principal components were appropriate in order to summarize the binder properties, while all variables were reflected in at least one of the PCs. A fourth PC did not distinctly increase the cumulative $\mathrm{Q}^{2}$ - or $\mathrm{R}^{2}$-values and was therefore disregarded for the model.

As indicated by the $\mathrm{R}^{2}$-bars in the summary of fit (Figure 8), the three principal components explained $93.4 \%$ of the overall variability in the binders` data set (i.e. $46.1 \%$ for $1^{\text {st }} \mathrm{PC}, 28.0 \%$ for $2^{\text {nd }} \mathrm{PC}$ and $19.2 \%$ for $3^{\text {rd }} \mathrm{PC}$ ).

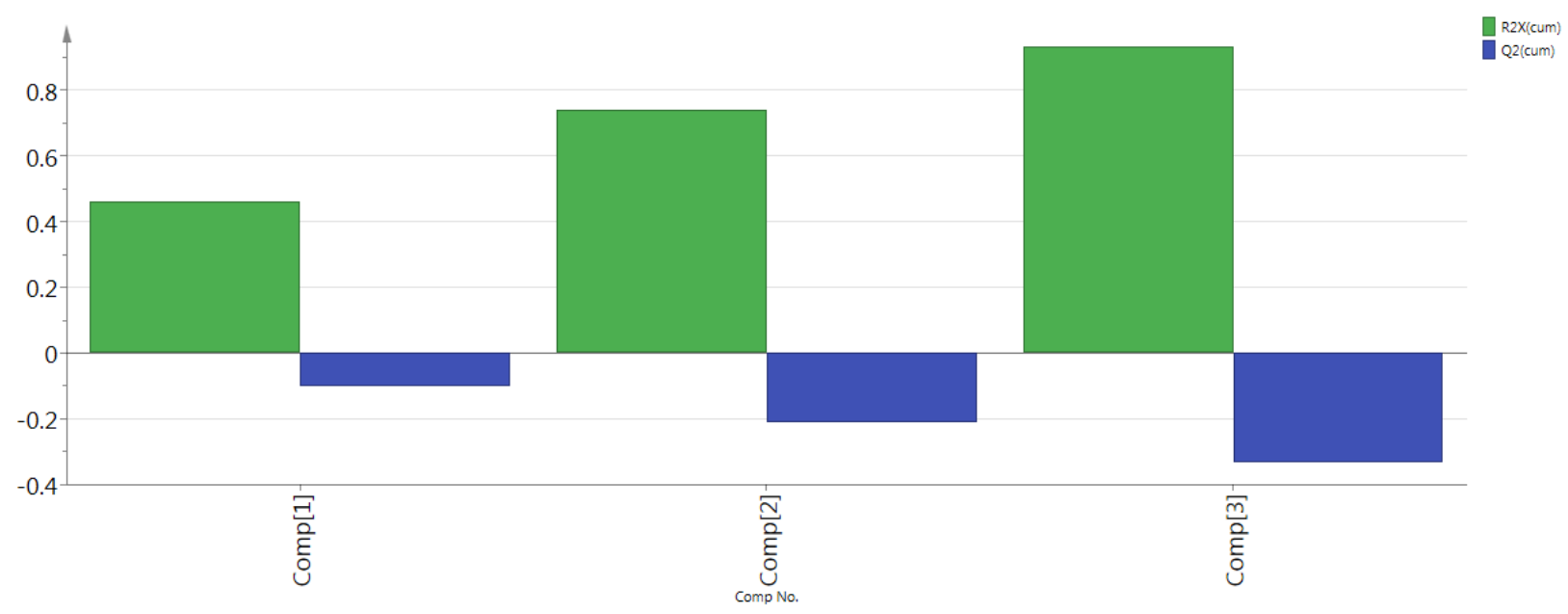

Figure 8. Summary of fit for binders 
The negative $\mathrm{Q}^{2}$ values indicated that prediction by applying the cross validation technique was not reliable for the binder data set, which might be attributed to the rather small data set used for PCA with only 5 properties characterized for 9 binders. The interpretation of the PCs for the binders was performed based on the coefficient scatter plots (Figure 9 and Figure 10) following the same approach as previously described for the fillers data set.

The first PC mainly described viscosity variability, the PC 2 mainly captured surface tension variability among the binders and the third PC was a representative of the binders` variability in glass transition temperature. Accordingly, viscosity, surface tension and glass transition temperature could be identified to be important properties while the major variation of $46.1 \%$ was explained by viscosity properties in the binder data set. Moreover, no clear correlation among the single binder properties was observed.

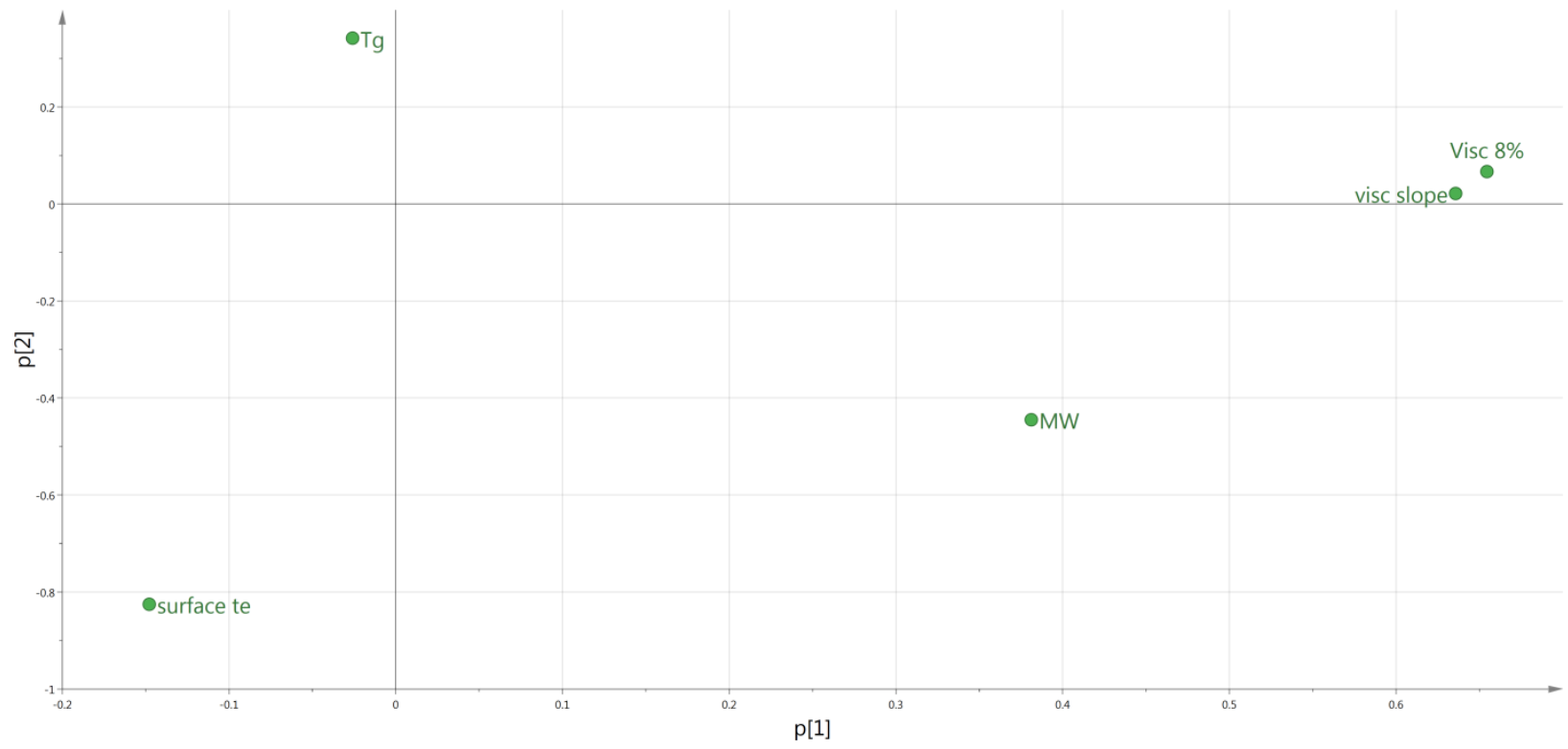

Figure 9. Loading scatter plot of binders` $1^{\text {st }}$ and $2^{\text {nd }} \mathrm{PC}$

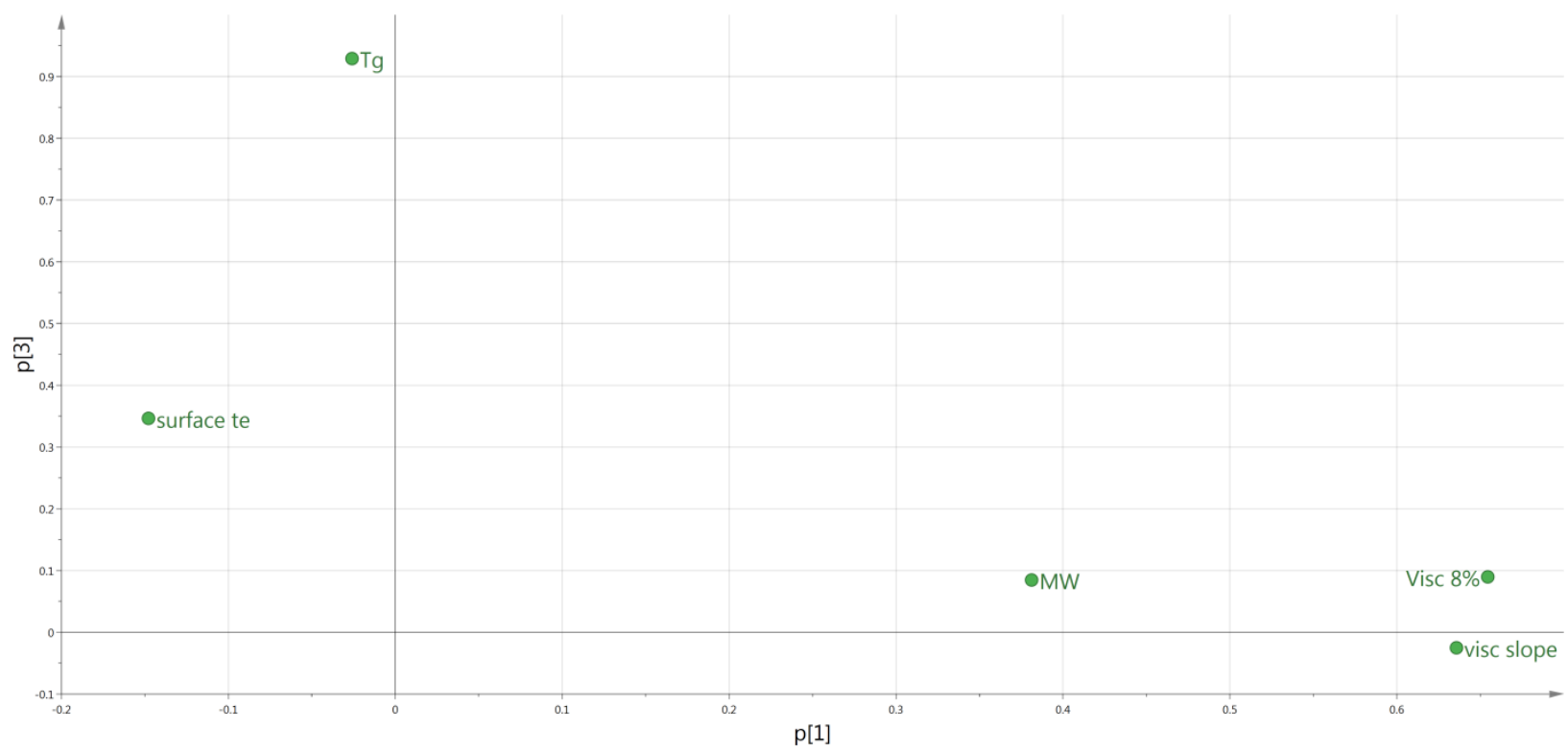

Figure 10. Loading scatter plot of binders` 1 st and $3^{\text {rd }} \mathrm{PC}$ 


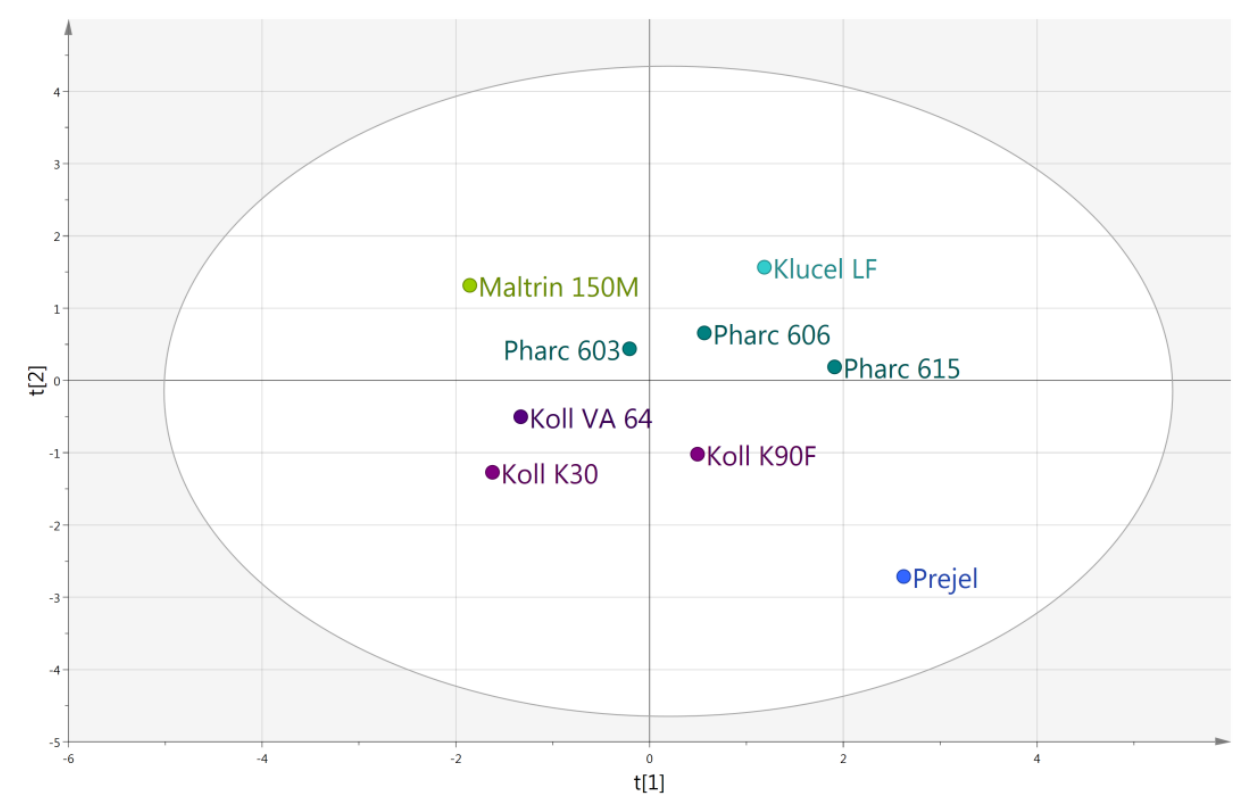

Figure 11. Scores plot PC1 vs. PC2 (binders) - Colours indicate chemical nature of binders

The PC 1 versus PC 2 scores plot showed that the binders were not clustered according to their chemical nature with respect to their principal properties explained by PC1 and PC2 (Figure 11).

Pharmacoat 615 had the highest viscosity of the three Pharmacoat grades included in this study and hence had a high positive PC1 score whereas Pharmacoat 603 with a low viscosity had a negative PC1 score value. The same fact was observed for the Kollidon polymers where Kollidon K90 had the highest PC1 score as a result of its high viscosity. Prejel had a negative PC2 score value which was in alignment with its high molecular weight for example. Due to insufficient solubility the viscosity and surface tension of an aqueous solution of Prejel could not be determined. However, according to the model Prejel should have a high viscosity which was in alignment with literature [23].

\section{Conclusion}

To conclude, PCA of the filler and binder data set allowed to reveal similarities and differences in excipient characteristics among materials of different chemical nature as well as between material grades. Moreover, PCA enabled to identify the excipient properties which were responsible for the differences and similarities between the excipients. The analysis also helped to understand which excipient properties were correlated or anti-correlated and which were not important in the underlying excipient property data set. Applying common pharmaceutical knowledge, the distribution of the excipients in the model space was in good agreement with the overarching properties which were assigned to the four principle components. The excipients selected for this study covered a broad range of material properties with the idea that also properties of other excipients which were not considered in this study might fall within these ranges. In addition, the database can be expanded by adding newly characterized excipients of interest. Also an expansion of the database with API data is possible. Therefore, the new excipients or APIs would need to be characterized applying the described characterization methods. In general, adding new data to the model is expected to result in an improved new model as it will be based on a larger data set with potentially more diverse excipient properties. As indicated in Figure 1, this research work is aimed to be used for a property-based selection of excipients to be processed in a continuous twin screw wet granulation process and to support a systematic investigation of formulation property impact on product and process performance. By using the principle components of the fillers and binders PCA 
models as factors in a DoE, the number of DOE experiments can be substantially reduced while all underlying excipient properties are still indirectly reflected and covered by the experimental design. 
Appendix

Table 4. Numerical values of descriptors used for PCA of fillers

\begin{tabular}{|c|c|c|c|c|c|c|c|c|c|c|c|c|c|c|c|c|c|c|c|c|c|c|c|}
\hline $\begin{array}{l}\text { Descriptive filler characteristic } \\
\text { (units) }\end{array}$ & $\begin{array}{l}\text { Particle size } \\
\text { distribution } \\
\text { D50 (in } \mu \mathrm{m} \text { ) }\end{array}$ & $\begin{array}{l}\text { Span of particle } \\
\text { size distribution } \\
\text { (dimensionless) }\end{array}$ & $\begin{array}{c}\text { Bulk } \\
\text { density } \\
\text { (in g/ml) }\end{array}$ & $\begin{array}{c}\text { Compressibil } \\
\text { ity index } \\
\text { (in \%) }\end{array}$ & $\begin{array}{l}\text { Moisture } \\
\text { content } \\
\text { (in \%) }\end{array}$ & $\begin{array}{c}\begin{array}{c}\text { Degree of } \\
\text { crystallinity } \\
\text { (in \%) }\end{array} \\
\end{array}$ & $\begin{array}{c}\text { Shape of } \\
\text { particles } \\
\text { (dimension- } \\
\text { less) }\end{array}$ & $\begin{array}{c}\text { True } \\
\text { density } \\
\left.\text { (in } \mathrm{g} / \mathrm{cm}^{3}\right)\end{array}$ & $\begin{array}{l}\text { Specific } \\
\text { surface } \\
\text { area } \\
\left(\mathrm{in}^{2} / \mathrm{g}\right) \\
\end{array}$ & $\begin{array}{l}\text { DVS } \\
\text { amount } \\
\text { of water } \\
\text { uptake } \\
\text { (in } \% \text { ) } \\
\end{array}$ & $\begin{array}{l}\text { DVS water } \\
\text { uptake ratio } \\
\text { (in } \mathrm{min} / \% \text { ) }\end{array}$ & $\begin{array}{c}\text { Flowability } \\
\text { (dimension- } \\
\text { less) }\end{array}$ & $\begin{array}{c}\text { Molecular } \\
\text { weight } \\
\text { (in Da) } \\
\end{array}$ & $\begin{array}{c}\text { Solubility } \\
\text { in water } \\
(\text { in } \%) \\
\end{array}$ & $\begin{array}{c}\text { Dissolution } \\
\text { kinetics } \\
\text { (in } \mathrm{mg} / \mathrm{sec} \text { ) }\end{array}$ & $\begin{array}{l}\text { Dynamic } \\
\text { Hardness } \\
\text { (in MPa) } \\
\end{array}$ & $\begin{array}{c}\text { Wettability - } \\
\text { Contact } \\
\text { angle } \\
\left(\text { in }{ }^{\circ}\right) \\
\end{array}$ & $\begin{array}{l}\text { Dynamic } \\
\text { flow- } \\
\text { flow } \\
\text { angle } \\
\left.\text { (in }{ }^{\circ}\right) \\
\end{array}$ & $\begin{array}{c}\text { Dynamic } \\
\text { flow - } \\
\text { cohesive } \\
\text { index } \\
\left.\text { (in }{ }^{\circ}\right) \\
\end{array}$ & $\begin{array}{c}\text { Dynamic } \\
\text { flow - } \\
\text { change of } \\
\text { flow angle } \\
\text { (dimension- } \\
\text { less) }\end{array}$ & $\begin{array}{c}\text { Dynamic } \\
\text { flow- } \\
\text { change of } \\
\text { cohesive } \\
\text { index } \\
\text { (dimension- } \\
\text { less) }\end{array}$ & $\begin{array}{c}\text { Electrostatic } \\
\text { charge } \\
\text { (in } \mu \mathrm{C} / \mathrm{kg} \text { ) }\end{array}$ & $\begin{array}{l}\text { Cohesiveness } \\
\text { (dimension- } \\
\text { less) }\end{array}$ \\
\hline Abreviation for variable in PCA & D50_PSD & Span_PSD & $\begin{array}{c}\text { bulk } \\
\text { density }\end{array}$ & comprindex & $\angle O D$ & $\begin{array}{c}\text { deg } \\
\text { crystallinity }\end{array}$ & aspRat50 & $\begin{array}{c}\text { true } \\
\text { density }\end{array}$ & SSA & $\begin{array}{c}\text { moisture } \\
\text { uptake }\end{array}$ & $\begin{array}{c}\text { water } \\
\text { uptake ratio }\end{array}$ & $\mathrm{ffc}$ & $\mathrm{MW}$ & solubility & $\begin{array}{l}\text { Diss } \\
\text { rate }\end{array}$ & $\begin{array}{l}\text { Hardness_- } \\
\text { Dynamic }\end{array}$ & $\begin{array}{c}\text { contact } \\
\text { angle }\end{array}$ & $\begin{array}{l}\text { flow } \\
\text { angle }\end{array}$ & $\begin{array}{c}\text { conhesive } \\
\text { index }\end{array}$ & slope_FA & slope_Cl & $\begin{array}{c}\text { net charge } \\
\text { density }\end{array}$ & $A R$ \\
\hline \multicolumn{24}{|l|}{ Name of filler } \\
\hline Avicel PH 101 & 61 & 2.02 & 0.308 & 25.95 & 4.07 & 56.7 & 0.44 & 1.5656 & 1.00 & 11.55 & 9.45 & 3.19 & 36000.0 & 0 & 0.008 & 240 & 38.3 & 54.0 & 34.6 & 0.2675 & 0.1487 & -4.622 & 10.76 \\
\hline Avicel PH 105 & 19 & 1.99 & 0.313 & 34.62 & 3.10 & 53.9 & 0.51 & 1.5499 & 1.70 & 11.85 & 6.95 & 1.84 & 36000.0 & 0 & 0.008 & 243 & 43.7 & 57.0 & 47.1 & 0.1358 & -0.3203 & -3.333 & 42.02 \\
\hline Avicel PH 301 & 63 & 2.00 & 0.433 & 23.45 & 3.60 & 57.2 & 0.47 & 1.5568 & 0.40 & 19.69 & 6.63 & 3.48 & 36000.0 & 0 & 0.008 & 200 & 40.3 & 44.1 & 28.0 & 0.1308 & 0.3639 & -3.333 & 15.11 \\
\hline Granulac 200 & 33 & 2.81 & 0.543 & 31.51 & 0.50 & 100.0 & 0.62 & 1.5405 & 0.60 & 0.32 & 42.13 & 1.80 & 360.3 & 16 & 7.952 & 79 & 19.4 & 44.8 & 36.6 & -0.4556 & -1.1932 & -3.787 & 29.35 \\
\hline Pharmatose $200 \mathrm{M}$ & 45 & 2.71 & 0.578 & 32.05 & 0.53 & 100.0 & 0.60 & 1.5439 & 0.50 & 0.20 & 116.65 & 2.17 & 360.3 & 16 & 8.110 & 38 & 19.3 & 34.3 & 33.5 & -0.4485 & -1.0579 & -2.560 & 15.95 \\
\hline Pharmatose $350 \mathrm{M}$ & 30 & 2.64 & 0.510 & 29.88 & 0.43 & 100.0 & 0.62 & 1.5383 & 0.50 & 0.21 & 134.15 & 1.54 & 360.3 & 16 & 8.227 & 74 & 15.9 & 53.6 & 53.4 & 0.1193 & 0.2860 & -6.560 & 27.80 \\
\hline Parteck M200 & 126 & 2.10 & 0.519 & 11.54 & 0.13 & 100.0 & 0.74 & 1.4928 & 3.20 & 0.70 & 53.90 & 7.28 & 182.2 & 15 & 11.561 & 275 & 43.5 & 35.4 & 10.7 & 0.3743 & 0.3428 & -3.440 & 31.46 \\
\hline Parteck Delta M & 65 & 3.54 & 0.460 & 26.14 & 0.10 & 100.0 & 0.50 & 1.5012 & 0.50 & 0.34 & 86.63 & 2.17 & 182.2 & 15 & 13.080 & 180 & 48.4 & 42.6 & 36.1 & -0.7829 & -0.4216 & -2.129 & 29.21 \\
\hline Dicalcium phosphate anhydrous & 19 & 1.70 & 0.901 & 32.00 & 0.27 & 100.0 & 0.71 & 2.8767 & 2.10 & 0.31 & 88.32 & 3.95 & 136.1 & 0 & 0.008 & 269 & 17.3 & 40.7 & 20.7 & -0.3828 & -0.6073 & -2.360 & 89.53 \\
\hline
\end{tabular}


Table 5. Numerical values of descriptors used for PCA of binders. (*Values could not be measured as it was not possible to fully disperse Prejel in water.)

\begin{tabular}{|c|c|c|c|c|c|}
\hline $\begin{array}{l}\text { Descriptive binder characteristic } \\
\text { (units) }\end{array}$ & $\begin{array}{l}\text { Dynamic } \\
\text { Viscosity } \\
\text { (in mPas) }\end{array}$ & $\begin{array}{l}\text { Change in } \\
\text { Viscosity } \\
\text { (dimension- } \\
\text { less) }\end{array}$ & $\begin{array}{l}\text { Molecular } \\
\text { weight } \\
\text { (in Da) }\end{array}$ & $\begin{array}{l}\text { Glass } \\
\text { transition } \\
\text { temperature } \\
\left(\text { in }{ }^{\circ} \mathrm{C} \text { ) }\right.\end{array}$ & $\begin{array}{l}\text { Surface } \\
\text { tension } \\
(\text { in } \mathrm{mN} / \mathrm{m} \text { ) }\end{array}$ \\
\hline Abreviation for variable in PCA & visc $8 \%$ & visc slope & $\mathrm{MW}$ & $\operatorname{Tg}$ & $\begin{array}{l}\text { surface } \\
\text { tension }\end{array}$ \\
\hline \multicolumn{6}{|l|}{ Name of binder } \\
\hline Pharmacoat 603 & 27.9 & 0.31 & 16000 & 141 & 45.9 \\
\hline Pharmacoat 606 & 145.0 & 0.35 & 35600 & 151 & 44.4 \\
\hline Pharmacoat 615 & 602.0 & 0.60 & 60000 & 158 & 50.3 \\
\hline Kollidon K30 & 5.2 & 0.12 & 49000 & 161 & 67.3 \\
\hline Kollidon K90F & 89.3 & 0.30 & 2250000 & 178 & 60.3 \\
\hline Klucel LF & 328.0 & 0.39 & 96000 & 182 & 38.9 \\
\hline Kollidon VA 64 & 4.8 & 0.11 & 58500 & 108 & 48.1 \\
\hline Prejel & ---* & ---* & 76200000 & 125 & ---* \\
\hline Maltrin 150M & 3.3 & 0.08 & 5950 & 177 & 42.6 \\
\hline
\end{tabular}




\section{References}

[1] P. Hurter, AAPS Newsmagazine - August 2013 - Implementing Continuous Manufacturing to Streamline and Accelerate Drug Development, (n.d.). http://www.nxtbook.com/nxtbooks/aaps/newsmagazine_201308/index.php?startid=14\#/ 14 (accessed May 19, 2016).

[2] ICH Guidance for Industry Q8(R2) Pharmaceutical Development, (n.d.). http://www.fda.gov/downloads/Drugs/.../Guidances/ucm073507.pdf (accessed May 17, 2016).

[3] E.I. Keleb, A. Vermeire, C. Vervaet, J.P. Remon, Single-step granulation/tabletting of different grades of lactose: a comparison with high shear granulation and compression, Eur. J. Pharm. Biopharm. 58 (2004) 77-82. doi:10.1016/j.ejpb.2004.03.007.

[4] A.S. El Hagrasy, J.R. Hennenkamp, M.D. Burke, J.J. Cartwright, J.D. Litster, Twin screw wet granulation: Influence of formulation parameters on granule properties and growth behavior, Powder Technol. 238 (2013) 108-115. doi:10.1016/j.powtec.2012.04.035.

[5] M. Fonteyne, A. Correia, S. De Plecker, J. Vercruysse, I. Ilić, Q. Zhou, C. Vervaet, J.P. Remon, F. Onofre, V. Bulone, T. De Beer, Impact of microcrystalline cellulose material attributes: A case study on continuous twin screw granulation, Int. J. Pharm. 478 (2015) 705-717. doi:10.1016/j.ijpharm.2014.11.070.

[6] M. Fonteyne, H. Wickström, E. Peeters, J. Vercruysse, H. Ehlers, B.-H. Peters, J.P. Remon, C. Vervaet, J. Ketolainen, N. Sandler, J. Rantanen, K. Naelapää, T.D. Beer, Influence of raw material properties upon critical quality attributes of continuously produced granules and tablets, Eur. J. Pharm. Biopharm. 87 (2014) 252-263. doi:10.1016/j.ejpb.2014.02.011.

[7] H. Li, M.R. Thompson, K.P. O’Donnell, Examining drug hydrophobicity in continuous wet granulation within a twin screw extruder, Int. J. Pharm. 496 (2015) 3-11. doi:10.1016/j.ijpharm.2015.07.070.

[8] R. Meier, M. Thommes, N. Rasenack, M. Krumme, K.-P. Moll, P. Kleinebudde, Simplified formulations with high drug loads for continuous twin screw granulation, Int. J. Pharm. 496 (2015) 12-23. doi:10.1016/j.ijpharm.2015.05.060.

[9] V. Vanhoorne, B. Vanbillemont, J. Vercruysse, F. De Leersnyder, P. Gomes, T.D. Beer, J.P. Remon, C. Vervaet, Development of a controlled release formulation by continuous twin screw granulation: Influence of process and formulation parameters, Int. J. Pharm. 505 (2016) 61-68. doi:10.1016/j.ijpharm.2016.03.058.

[10] M.R. Thompson, K.P. O'Donnell, "Rolling" phenomenon in twin screw granulation with controlled-release excipients, Drug Dev. Ind. Pharm. 41 (2015) 482-492. doi:10.3109/03639045.2013.879723.

[11] M.R. Thompson, Twin screw granulation - review of current progress, Drug Dev. Ind. Pharm. 41 (2015) 1223-1231. doi:10.3109/03639045.2014.983931.

[12] L. Eriksson, E. Johansson, N. Kettaneh-Wold, J. Trygg, Multi- and Megavariate data Analysis, Basic Principles and Applications, Second edition, Umetrics Academy, n.d.

[13] M. Wada, T. Okano, J. Sugiyama, Synchrotron-radiated X-ray and neutron diffraction study of native cellulose, Cellulose. 4 (1997) 221-232.

[14] D. Schulze, Powders and Bulk Solids, Springer Berlin Heidelberg, Berlin, Heidelberg, 2007. http://link.springer.com/10.1007/978-3-540-73768-1 (accessed May 17, 2016).

[15] European Pharmacopoeia, Version 8.8, n.d.

[16] C.K. Tye, C. (Calvin) Sun, G.E. Amidon, Evaluation of the effects of tableting speed on the relationships between compaction pressure, tablet tensile strength, and tablet solid fraction, J. Pharm. Sci. 94 (2005) 465-472. doi:10.1002/jps.20262. 
[17] S. Pirard, G. Lumay, N. Vandewalle, J. Pirard, Motion of carbon nanotubes in a rotating drum: The dynamic angle of repose and a bed behavior diagram, Chem. Eng. J. 146 (2009) 143-147. doi:10.1016/j.cej.2008.09.015.

[18] R.C. Rowe, ed., Handbook of pharmaceutical excipients, 6. ed, APhA, (PhP) Pharmaceutical Press, London, 2009.

[19] P. Liu, L. Yu, H. Liu, L. Chen, L. Li, Glass transition temperature of starch studied by a high-speed DSC, Carbohydr. Polym. 77 (2009) 250-253. doi:10.1016/j.carbpol.2008.12.027.

[20] J. Karseboom, Information Tg of Prejel, (n.d.).

[21] MALTRIN® Maltodextrin + Corn Syrup Solid Applications | Agglomeration + Wet Granulation | maltodextrins + corn syrup solids | Nutra, (n.d.). $\mathrm{http}: / / \mathrm{www}$.grainprocessing.com/maltodextrins-corn-syrup-solids/agglomeration-wetgranulation.html (accessed June 30, 2016).

[22] Brochure - Parteck M qualities, (n.d.).

[23] Charles Cunningham, Starch Contrasts - Knowing the differences among pregelatinized starches will produce desired formulation release rates, (n.d.). 